\title{
Genetic Similarity of Pomegranate Genotypes Grown in Siirt Province
}

\author{
Mine Pakyürek \\ Department of Horticulture Faculty of Agriculture Siirt University 56100 Siirt Turkey \\ Corresponding author: mine.pakyurek@siirt.edu.tr
}

\begin{abstract}
Siirt is famous with its pomegranate which is called Zivzik and is an important livelihood of the region. Zivzik pomegranate is a variety registered in 2008 and geographic sign studies are currently underway. Due to the genetic diversity of Siirt region, there are different genotypes not registered there yet. This is the first study carried out to investigate relationship status of Zivzik (Punica granatum L.) and Şirvan pomegranates by constructing the phylogenetic trees. 30 genotypes studied were numbered from 1 to 30 in our experiment. Four of 30 genotypes, which have different fruit characteristics from Zivzik variety, were included in the study. These four genotypes are called as Asili (Genotype 21), sour pomegranate (Genotype 22 and 23) and red pomegranate (Genotype 24). Neighbor Joining (NJ) and Bootstrap analysis were used to generate dendrogram showing the genetic relationship of Zivzik pomegranate, which is the most well-known genetic resource in Southeastern Anatolia region of Turkey. The phylogenetic tree of genotypes indicated that genotypes 9, 18, 21, 6, 24 and 7; genotypes 17, 13, 12, 4 and 3 and genotypes 5, 8, 20, 11, 19, 2 and 27 were substantially similar. Genotypes 29, 16 and 14, in terms of physiological properties, were located at the furthest position on the phylogenetic tree from the other genotypes.
\end{abstract}

Keywords: Punica granatum L., ITS regions, phylogenetic tree, genetic diversity, molecular analysis.

DOI: $10.7176 / \mathrm{JBAH} / 9-20-03$

Publication date:October $31^{\text {st }} 2019$

\section{Introduction}

Pomegranate belongs to the genus Punica and is widely distributed in Mediterranean region, Asia, North Africa, Europe and Indian peninsula (Levin, 2006). The pomegranate is one of the oldest edible fruit species, cited in the Bible and the Qur'an and known to be cultivated back to the 3000-4000s (Chandra et al., 2010). The first traces of pomegranate cultivation were found in Transcaucasia-Caspian region and the northern regions of Turkey (Zohary, 1975; Harlan, 1992). Pomegranate is grown under diverse climatic conditions in subtropical and tropical regions of the world. However, the largest commercial production takes place in Mediterranean countries followed by Asian countries (Silva et al., 2013). Pomegranate is a shrub-shaped plant with length ranging from 2 to 5 meters (Ebcioğlu, 2003). The fruits consist of multi fleshy seeds which the color can change from dark-red to white. The fruits, containing high levels of potassium and carbohydrates, are classified as sweet, tart and sour.

Development of molecular markers, which are superior to morphological and biochemical markers, enabled to obtain rapid and reliable results by conducting studies with no time limitations (Yıldırım and Kandemir, 2001). Molecular markers originate from DNA found in plant cells. The codes defining the structure of living organisms are located in DNA chains, therefore the relationships between diversity in the plant population or plant genotypes within the population can be determined by using molecular markers at almost $100 \%$ reliability. Molecular markers are used in several studies to improve the quality and quantity of fruit production. Molecular markers are widely used in fruit growing, such as genotypic identification, systematic and characterization, genetic and quantitative trait loci mapping, marker selection and conservation of genetic resources (Andersen and Lübberstedt, 2003; Kaçar, 2004; Vardar-Kanlıtepe et al., 2010).

Zivzik pomegranate is a variety registered in 2008 by the Pistachio Research Institute located in Gaziantep, Turkey. While Siirt region has a continental climate, Zivzik pomegranate is grown in the region where micro climate is seen in the foothills of Botan River Valley. There are covered orchards in this region where commercial breeding is carried out. This variety is an important source of livelihood for the regional producer. Zivzik pomegranate is a variety with medium size fruits, high in taste-aroma and fruit juice, and suitable for storage about 6 months. Since Southeastern Anatolia is the homeland of the pomegranate, there are also different genotypes grown in the region that have not yet been registered as varieties. Pomegranates grown in the region have sweet, tart and sour tastes. So far molecular level study has not been conducted to reveal the genetic diversity of these pomegranate genotypes grown in the region. That is why our study was carried out to investigate the similarity status and to determine the genetic diversity of 30 pomegranate genotypes belong to Siirt district located in Southeastern region of Turkey. With this purpose, ITS1 and ITS2 regions of 30 pomegranate genotypes were amplified by PCR technique and the phylogenetic tree of the genotypes was constructed. Southeastern Anatolia region is the gene center of many fruit species; therefore, the region has a 
high genetic diversity. For that reason, the findings obtained in this study are important to determine and preserve the gene source potential of Zivzik and Şirvan pomegranates.

\section{Methodology}

\subsection{Pomegranate Genotypes}

Pomegranate genotypes belong to Zivzik and Şirvan pomegranates were collected from the five different orchards located in Sarıdana, Kapılı, Pirinçli and Zivzik villages of Şirvan district of Siirt province in Southeastern Anatolia, Turkey. The genotypes studied were known with their superior yield and quality characteristics and were numbered from 1 to 30 . Four of 30 genotypes, which have different fruit characteristics from Zivzik variety, were included in the study. These four genotypes are called as Asili (Genotype 21), sour pomegranate (Genotype 22 and 23) and red pomegranate (Genotype 24). Leaf samples from different genotypes were collected in spring and samples were stored at $-20{ }^{\circ} \mathrm{C}$ until molecular analyses performed.

\subsection{Molecular and Phylogenetic Analysis}

Genomic DNA isolation of genotypes was performed according to the CTAB (Cetyl Trimethyl Ammonium Bromide) method (Doyle and Doyle, 1987). The quality of isolated DNAs was determined using a Nanodrop (Thermo) in a $1 \%$ gel. The ITS regions (ITS1 and ITS2) were amplified using the ITS4 primer by PCR technique. Total volume to the PCR reaction was set to $25 \mu \mathrm{l}$ by adding $3 \mu \mathrm{l}$ (100 ng) template DNA, $2.5 \mu 1$ 10X Taq buffer, $3 \mu \mathrm{MgCl}_{2}, 1 \mu \mathrm{l}$ forward-reverse primers, $10 \mathrm{mM}$ dNTP mix, $0.25 \mu \mathrm{l}$ Taq polymerase and $13 \mu 1$ $\mathrm{ddH}_{2} \mathrm{O}$. Agarose gel (1\%) electrophoresis containing $1 \mu \mathrm{L}$ ethidium bromide was run to observe the bands formed after the PCR and the quality of the band was assessed under UV light. The results of PCR were sent to Medsantek Company (Istanbul/Turkey) for sequencing. Neighbor Joining (NJ) and Bootstrap analysis methods were used to generate the genetic distance tree.

\section{Results and Discussions}

\subsection{Phylogenetic Tree of the ITS Regions}

Single gene tree is sufficient to determine the molecular phylogeny of the varieties within the same species. Therefore, the gDNA was amplified and a phylogenetic tree belonging to ITS regions was constructed. Neighbor-Joining (NJ) method which is one of the distance-based methods, was used to create a genetic distance tree. The bootstrap analysis was employed to evaluate the statistical reliability of the acquired tree branches. Kress et al. (2002) evaluated the bootstrap support criteria as; $>=85 \%$ strong, between $75 \%$ and $80 \%$ moderate, between $50 \%$ and $70 \%$ weak and $<50 \%$ very weak. The nodes of the phylogenetic tree show the bootstrap values of the genotypes in Figure 1. As seen from the phylogenetic tree, a large cluster group which includes three small clustering groups have formed on the upper part of the tree (Figure 1). Small clustering groups constituting the large group include genotypes 9, 18, 21 (Asili), 6, 24 (Red pomegranate) and 7; genotypes 17, 13, 12, 4 and 3; and genotypes 5, 8, 20,11, 19, 2 and 27. 


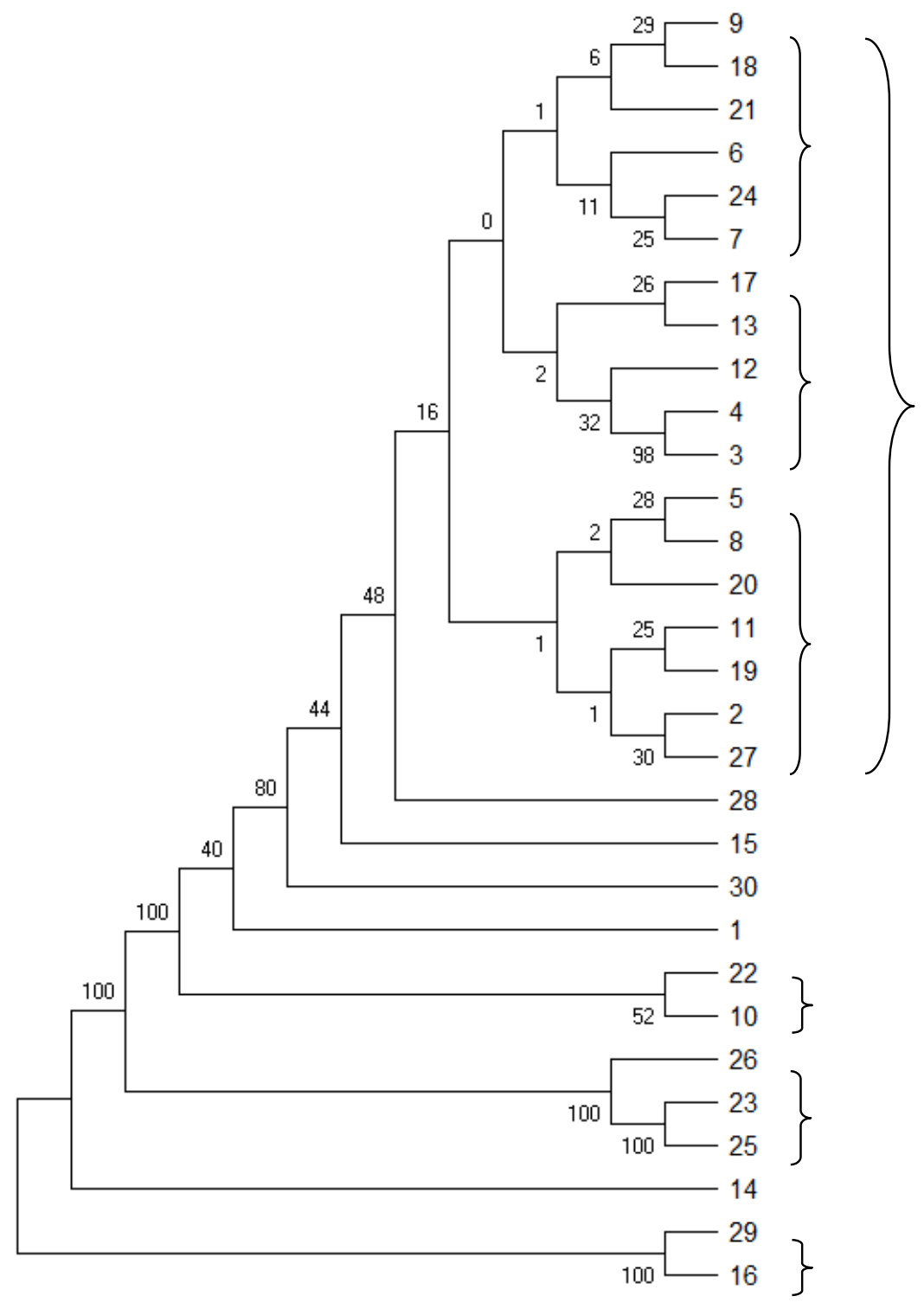

Figure 1. Phylogenetic tree constructed by Neighbor-Joining analysis of ITS regions.

Genotypes 28, 15, 30 and 1 externally attached to this large cluster group (Figure 1). For example; genotype 28 was connected to the large clustering group with a bootstrap value of $16 \%$. The low bootstrap value indicates that genotype 28 is slightly similar to this group. Although genotype 15 had a higher bootstrap value (48\%) than the genotype 28, both bootstrap values are considered weak according to Kress et al. (2002).

Similar to the upper portion of the phylogenetic tree, three small clusters were occurred at the bottom of the tree. A group of genotypes 22 (sour pomegranate) and 10 are connected to each other with a bootstrap value of $52 \%$ and genotypes 26, 23 (sour pomegranate) and 25 form a cluster group with $100 \%$ bootstrap value. Genotypes 29 and 16 constitute the third small cluster that is connected from the outside to the large cluster with a $100 \%$ bootstrap value (Figure 1). Genotype 14 is also connected to the large cluster separately with $100 \%$ bootstrap value. The findings show that the genotypes 29, 16 and 14 are placed in the furthest position from other genotypes on the phylogenetic tree in terms of physiological properties.

Different phylogenetic studies have recently been carried out to determine the pomegranate. Qin et al. (2017) has confirmed that the pomegranate and eucalyptus come from the same common ancestor, Myrtales, and have formed the pomegranate genome. Similarly, a new pomegranate genome sequence was found to understand the fertilization biology and fruit characteristics of pomegranate and to enlighten the existing breeding studies 
(Yuan et al., 2018). In addition, different phylogenetic studies have been conducted to investigate the similarity degree of the varieties within the different species as well. For example; the ITS and trnLf regions were amplified and the phylogenetic relationship between the Asparagus species was examined by different researchers as similar our experiment (Altıntaş et al., 2019). Researchers achieved to construct phylogenetic tree of the Asparagus species from the ITS and trnLf regions in an other trial. The similarity percentage of the Asparagus species were compared by the RAPD method (Fukuda et el., 2012). Fidan et al. (2018) succeeded a study using 20 local grape varieties and the researchers isolated the cpDNA and amplified the trnLf region to construct the phylogenetic tree of the varieties. Inal et al. (2017) accomplished to construct a phylogenetic tree of the some Turkish apple genotypes. Some researchers performed to form the phylogenetic tree of 15 local Turkish pear genotypes in one another experiment carried out in the Siirt province (Özrenk et al., 2018).

\section{Conclusion}

The phylogenetic tree revealed information on similarity status and similarity relationship between the existing 30 genotypes. As a conclusion, our findings confirm that 26 genotypes examined were clones of Zivzik pomegranate. Having high similarity rates of these 26 genotypes and their branching status on the phylogenetic tree reveal this result. When it comes to other four genotypes (21-Asili, 22-Sour pomegranate, 23-Sour pomegranate and 24-Red pomegranate) which are thought to be potentially different varieties due to their different pomological properties from Zivzik variety; it is concluded that these genotypes are also genetically close related to Zivzik pomegranate. Pomegranate is a species of fruit produced with cuttings without grafting; thus, each new tree produced by cutting is a clone of that genotype. However, in the existing orchards, some trees may rarely be produced with seedling obtained by germination of the seeds. This possibility may lead to genetic expansion. Therefore, three small clusters formed on the upper part of the phylogenetic tree up to genotype 28. The binding of these clusters means that all these genotypes are clones within the same species. Genotypes 21 and 24 are expected to bind externally to these clusters, however, while these genotypes remained within the cluster. Low bootstrap values of genotype $21(6 \%)$ and 24 (11\%) indicated a weak similarity of 21 and 24 to other genotypes. Genotypes 22 and 23 are externally bound to the largest cluster as expected. The binding of genotype 22 to the large cluster with a $40 \%$ bootstrap is indicative of low genetic similarity with these genotypes.

Morphological, phenological, pomological and molecular analyzes should be performed all together to make better taxonomic classification of genotypes within the same genus and species. In our pioneering research, no variation was found in the ITS regions obtained by amplification of genomic DNA to support that the genotypes (Genotypes 21, 22, 23, 24), which are considered to be 4 different varieties from Zivzik pomegranate clones, are different varieties on the phylogenetic tree. Therefore, amplification of trnL intron regions by using chloroplast DNA as well as genomic DNA in terms of amplified gene regions may allow observing a wider variation. Seedlings of genotypes and other clones, which are thought to be varieties, should be grown in equal conditions in an orchard. Following the phenological and pomological characteristics and considering these genotypes in registration studies are important for the protection of pomegranate gene resources and the development of new breeding studies.

Acknowledgement: This study was funded by Scientific Research Project Council, Siirt University with the project no 2018-Sİ̈ZZIR-030.

\section{References}

Altıntaş, S., Pakyürek, M., Şensoy, S., Erez, M.E. and İnal, B. (2019), Genetic diversity among some Asparagus species using rDNA ITS, cpDNA trnL intron sequence and screening for antioxidant activity. Polish Journal of Environmental Studies. 28(4) 1-7.

Andersen, J.R. and Lübberstedt, T. (2003), Functional markers in plants. Trends in Plant Science. 8(11) 554-560.

Chandra, R., Babu, D.K., Jadhav, V.T. and Silva, J.A.T. (2010), Origin, history and domestication of pomegranate. In: Chandra, R. (Ed.), Pomegranate. Fruit Veg. Cereal Sci. Biotechnol. 4(2) 1-6.

Doyle, J.J. and Doyle J.L. (1987), A rapid DNA isolation procedure from small quantities of fresh leaf tissues. Phytochem. Bull. 19 11-15.

Ebcioğlu, N. (2003), Definition of building blocks of our health vegetables and fruits, nutritional values, useful effects, production and cultivation (in Turkish). Remzi Bookstore. p. 208, İstanbul.

Fidan, M., Erez, M.E., İnal, B., Pınar, M.S. and Altıntaş, S. (2018), Antioxidant capacity and phylogenetic analysis of twenty native grape cultivars in Siirt province, Turkey. Cellular and Molecular Biology. 64(7) 14-18.

Fukuda, T., Song, In-Ja, Ito, T., Nakayama, H., Hayakawa, H., Minamiya, Y., Arakawa, R., Kanno, A. and Yokoyama, J. (2012), Comparing with phylogenetic trees inferred from cpDNA ITS sequences and RAPD analysis in the genus Asparagus (Asparagaceae). Environ. Control Biol. 50(1) 13-18. 
Harlan, J.R. (1992), Crops and Man, 2nd Edn. - American Society of Agronomy and Crop Science Society of America, Madison, WI. pp. 295.

Inal, B., Özrenk, K., Erez, M.E. and Altıntaş, S. (2017), The comparison of phenolic compounds content, antioxidant capacity and molecular analysis of some selected Turkish apple (Malus spp.) genotypes. Applied Ecology and Environmental Research. 15(4) 2035-2044.

Kaçar, Y.A. (2004), Use of molecular markers in prunus species. Alatarım. 3 (2) 15-22. (in Turkish).

Kress, W.J., Prince, L.M. and Williams, K.J. (2002), The phylogeny and a new classification of the gingers (Zingiberaceae): evidence from molecular data. American Journal Botany. 89, 1682-1696.

Levin, G.M. (2006), Pomegranate Roads: A Soviet Botanist's Exile from Eden. 1st Edn. Floreant Press, Forestville, California. pp. 15-183.

Özrenk, K., Erez, M.E., Altıntaş, S. and İnal, B. (2018), The comparison of phenolic compounds content, antioxidant capacity and molecular analysis of some selected Turkish pear genotypes. Fresenius Environmental Bulletin. 27(1) 584-589.

Qin, G., Xu, C., Ming, R., Tang, H., Guyot, R., Kramer, E. M., Hu, Y., Yi, X., Qi1, Y., Xu, X., Gao, Z., Pan, H., Jian, J., Tian, Y., Yue, Z. and Xu, Y. (2017), The pomegranate (Punica granatum L.) genome and the genomics of punicalagin biosynthesis. The Plant Journal. 91 1108-1128.

Silva, J.A.T., Rana, T.S., Narzary, D., Verma, N., Meshram, D.T. and Ranade, S.A. (2013), Pomegranate biology and biotechnology: A review. Scientia Horticulturae. 160 85-107.

Vardar-Kanlitepe, Ç., Aras, S. and Cansaran-Duman, D. (2010), Use of molecular markers in plant breeding and gene transfer. Turkish Journal of Hygiene and Experimental Biology. 33 (in Turkish).

Yıldırım, A. and Kandemir, N. (2001), Plant Biotechnology II. Gene Engineering and Applications. (Ed: Özcan S, Gürel E, Babaoğlu M,) Genetic Markers and Analysis Methods. Selçuk University, Konya. (in Turkish).

Yuan, Z., Fang, Y., Zhang, T., Fei, Z., Han, F., Liu, C., Liu, M., Xiaol, W., Zhang, W., Wu, S., Zhang, M., Ju, Y., Xu, H., Dai, H., Liu, Y., Chen, Y., Wang, L., Zhou, J., Guan, D., Yan, M., Xia, Y., Huang, X., Liu, D., Wei, H. and Zheng, H. (2018), The pomegranate (Punica granatum L.) genome provides insights into fruit quality and ovule developmental biology. Plant Biotechnology Journal. 16 1363-1374.

Zohary, D. and Spiegel-Roy, P. (1975), Beginnings of fruit growing in the old world. Science. 187, 319. 